\title{
AS TRADUÇÕES DE EL HOMBRE DE MI VIDA PARA O FRANCÊS E O PORTUGUÊS: LÉXICO E DIFERENCุA
}

\author{
THE TRANSLATIONS OFEL HOMBRE DE MI VIDA TO \\ FRENCH AND PORTUGUESE: LEXIC AND DIFFERENCE
}

\author{
Angélica Karim Garcia Simão 221 \\ Maria Angélica Deângeli ${ }^{222}$
}

RESUMO: $O$ presente trabalho objetiva tecer uma análise sobre as traduções da obra El hombre de mi vida (2000), do autor catalão Manuel Vázquez Montalbán (1939-2003), da língua espanhola para as línguas francesa, L'homme de ma vie, e portuguesa, $\mathrm{O}$ homem da minha vida. Reconhecendo a importância de elementos lexicais para a construção da textualidade literária e para a representação de personagens e de espaços narrativos, tenciona-se mostrar como o uso do léxico tabu, na fala do personagem protagonista (Pepe Carvalho) e em suas respectivas traduções, funciona como recurso discursivo e estilístico para ora acentuar, ora atenuar os paradoxos, desencantos e insatisfações da pós-modernidade. No que concerne às questões do léxico tabu, referimo-nos, sobretudo, aos trabalhos de Domínguez (2008) e Shadid (2011), os quais apresentam diferentes abordagens do tema, considerando suas origens e desdobramentos. Com relação às reflexões sobre tradução, apoiamo-nos nas pesquisas de Rodrigues (2000; 2012), que concebe a tradução como espaço da diferença, e de Crépon (2004/2016), para quem as culturas são constitutivamente traduções, remetendo, nesse sentido, a uma relação diferencial e a um movimento constante de desapropriação linguística. É

${ }^{221}$ Doutora em Letras - Língua espanhola - pela Universidade de São Paulo-USP. Professora do Departamento de Letras Modernas da Universidade Estadual Paulista "Júlio de Mesquita Filho"-UNESP e do Programa de Pós-graduação em Estudos Linguísticos-PPGEL-Unesp/São José do Rio Preto.

222 Doutora em Letras pela UNESP/SJRP. Professora do Departamento de Letras Modernas - Área de francês - da Universidade Estadual Paulista "Júlio de Mesquita Filho"-UNESP e do Programa de Pós-graduação em Estudos Linguísticos-PPGEL-Unesp/São José do Rio Preto. 
500 | Angélica Karim Garcia Simão, Maria Angélica Deângeli

sob a perspectiva da diferença linguística e cultural que empreendemos então a leitura das obras aqui mencionadas e de seus percursos tradutórios.

Palavras-chave: Tradução; léxico; diferença.

ABSTRACT: The present work aims to provide an analysis of the translations of El hombre de mi vida (2000), by the Catalan author Manuel Vázquez Montalbán (1939-2003), from Spanish into French, L'homme de ma vie, and Portuguese, $\mathrm{O}$ homem da minha vida. Recognizing the importance of lexical elements for the construction of literary textuality and for the representation of characters and narrative spaces, it is intended to show how the use of the lexicon tabu, in the speech of the protagonist character (Pepe Carvalho) and in the respective translations, functions as a discursive and stylistic resource, at times, to accentuate, and at other times to attenuate the paradoxes, disenchantments and dissatisfactions of postmodernity. Regarding the issues of the tabu lexicon, we refer mainly to the works of Domínguez (2008) and Shadid (2011), which present different approaches to this question, considering their origins and unfoldings. For the reflections on translation, we rely on the research of Rodrigues $(2000,2012)$, who conceives translation as a space of difference and Crépon (2004/2016), for whom cultures are essentially translations, referring in this sense, to a differential relationship and to a constant movement of linguistic expropriation. It is from the perspective of linguistic and cultural difference that we then undertake the reading of the works aforementioned and their translation paths.

Key-words: Translation; lexic; difference.

\section{Questões de tradução}

Se, como afirma Crépon (2004/2016), pensar a relação entre culturas é, de certo modo, pensar a tradução, isso significa dizer que é impossivel tratar as diferentes culturas como "entidades homogêneas" (p. 256). A diferença é constitutiva da tradução; é aquilo que a torna possível e (in)desejável. O desejo de conhecer o outro, de fazê-lo vir até mim em "minhas próprias palavras", é sempre turvado pela impossibilidade de sua realização. A tradução seria, assim, aquilo que ao me aproximar do outro efetua a desapropriação de minha própria língua. Segundo Crépon: 
As traduções de El hombre de mi vida para o francês e o português: léxico e diferença | 501

[a tradução] me aproxima daqueles que falam outras línguas (as línguas traduzidas), da mesma forma que o que se traduz na língua deles na minha língua os aproxima de mim e faz com que essa língua não seja mais de modo algum, ou pelo menos não mais exclusivamente, a minha. $\mathrm{O}$ que se turva com a tradução é o mapa do meu e do seu. (2016, p. 257)

Nesse movimento de desapropriação linguística e cultural, a palavra ocupa lugar de destaque, o próprio ato de traduzir parece centrarse, segundo as vias de um pensamento tradicionalista, na busca sempre ilusória pela palavra ideal. Segundo essa perspectiva, conforme ressalta Rodrigues (2000, p. 193), é como se tivéssemos "acesso às coisas do mundo por meio da linguagem”, como se o mundo e a cultura fossem a “fonte das representações" e não o seu "efeito". É nesse sentido também que se tece a crítica de Crépon a um pensamento "cosmopolita" segundo o qual, embora a diferença de culturas seja, muitas vezes, considerada, a mistura e a mestiçagem sejam tomadas no horizonte desse universo cultural supostamente cosmopolita, o que se sobressai é "o dogma de culturas homogêneas originais (idênticas a si mesmas) que devem aprender a coexistir ou que se misturam umas às outras, em um segundo tempo somente" (p. 260). A ideia de um segundo tempo faria então pressupor a existência de um "primeiro tempo", um lugar-tempo mítico que remetesse a uma origem pura, a um significante transcendental que existisse "fora da natureza diferencial dos signos" (RODRIGUES, 2000, p. 197).

Enquanto diferença, são os efeitos de sentido que a tradução convoca para a cena, uma palavra valendo não pelo que é, mas pelo que lhe escapa daquilo que ela não é. $O$ que lhe falta, o que nela não se revela, não pode então figurar como uma ausência secundária, um aposteriori diferencial, mas, ao contrário, está na origem de sua própria constituição, é falta constitutiva.

Assim quando se trata de comparar línguas diferentes, línguas em tradução, o trabalho deve voltar-se para o que apreendemos do que não foi possível dizer ou do que se disse de outra maneira, numa outra ausência. A tradução é, dessa forma, um trabalho de remissão permanente, uma palavra remetendo à (ausência) de outra em sua própria língua e em outra(s) línguas, e evocando sentidos imaginários e jamais 
502 | Angélica Karim Garcia Simão, Maria Angélica Deângeli

imaginados pelo autor-leitor-tradutor. É uma tessitura que constrói e descontrói sentidos, desfaz cadeias e reinventa significados e significantes.

O próprio da tradução, se é justo dizer que há algo de próprio na tradução, é sua capacidade de reinvenção, de dizer numa outra língua aquilo que lhe falta em sua própria língua. Isso implica um exercício constante de adaptação ao outro, de resposta ao apelo que o outro nos faz enquanto diferente e diferença. Tudo se tece numa ótica diferencial; nada, no que diz respeito à tradução, (lhe) é imanente. É também nesse sentido que se pode conceber a afirmação de Crépon segundo a qual "o que cada cultura imagina ter de próprio [...] é certamente efeito de uma tradução, até mesmo de uma sucessão de traduções - de tal maneira que será quase impossível separar o original do traduzido" (p. 265). É considerando as diferenças entre línguas, as línguas como diferenças, nos ditos e interditos de uma palavra já traduzida em sua origem, que nos voltamos então para a leitura de Manuel Vázquez Montalbán, mais precisamente para a obra El hombre de mi vida e suas traduções para o francês e o português.

\section{Questões de léxico}

Observamos no decorrer do século XX o acolhimento, na literatura nacional e traduzida, do vocabulário gírio, tido como pejorativo, como um recurso estilístico amplamente utilizado, sobretudo na esfera da narrativa policial, a fim de delinear o contorno marginalizado no qual se inserem as personagens de ficção. Embora muito presente, a análise crítica pouco se voltou para o estudo desse recurso como um fenômeno isoladamente. Esse tratamento secundário destinado ao léxico é atualmente muito questionado, visto que o seu papel é fundamental para construção dos sentidos, se consideradas suas propriedades como um importante recurso para atingir a dimensão da textualidade (ANTUNES, 2012, p. 24).

Pode-se considerar o léxico de uma língua como o repertório de representação de diferentes categorias, como reflexo das dimensões sociais e como expressão da identidade cultural que os sujeitos de uma comunidade manifestam ao longo do tempo, considerações que nos direcionam ao seu entendimento na esfera do discurso. Tais representações são armazenadas pelos falantes e "remetem ao conhecimento que o homem constrói em sua experiência social com grupos e culturas de que participa" (ANTUNES, 2012, p. 28). De acordo com Nunes (2006, p. 152): 
As traduções de El hombre de mi vida para o francês e o português: léxico e diferença | 503

A perspectiva discursiva, então, traz elementos para uma compreensão do léxico enquanto objeto linguístico afetado pelo discurso, ou seja, pelos processos históricos de significação. [...] $\bigcirc$ fato lexical é um fato social e, assim sendo, está sujeito às forças sociais, que permeiam as relações entre os sujeitos. Na articulação com o discurso, a descrição linguística atenta para esse fato, levando em consideração que as mesmas palavras podem ter sentidos diferentes, conforme as posições sustentadas pelos sujeitos.

Como todo instrumento discursivo, o léxico apresenta algumas peculiaridades que podem ser foco de estudo, como é o caso dos tabus linguísticos, entendidos aqui como disfemismos léxicos na forma de insultos, obscenidades, palavrões ou palavras vulgares utilizadas para designar o ato sexual ou as partes pudendas do corpo, também o léxico referente ao âmbito escatológico e grosseiro, considerado vulgar e de uso pejorativo ou depreciativo.

Segundo Shadid (2011), o tabu está sempre relacionado a uma proibição ou aversão a algum elemento social ou cultural geralmente ligado a questões como a morte, superstição, doença mental, falha moral, status financeiro, ofensa, escatologia, sexo, órgão sexual, dentre outros. São assuntos considerados socialmente "delicados" e que, normalmente, são evitados. Portanto, tabus fazem referência a temas controversos, que geram aversão ou repulsa pela sociedade; dessa forma, as unidades do léxico utilizadas para designar esses elementos são também consideradas tabus.

A autora ainda destaca que, segundo algumas perspectivas, o tabu está e sempre esteve presente na vida do ser humano, fazendo também parte de sua imersão na linguagem. Assim, o léxico de diferentes sociedades é composto por diversos tabus linguísticos, "cuja evasão ou substituição pretende atenuar o significado das palavras que provocam temor, repúdio ou pudor" 223 . (SHADID, 2011, p. 126)

Os tabus são encontrados em todas as sociedades, mesmo entre diferentes povos, o que muda são os objetos considerados tabus e os termos utilizados para se referir a eles (DOMÍNGUEZ, 2008). Nas sociedades em que o léxico tabu se manifesta também podem ser

223 "cuya evasión o sustitución pretende atenuar el significado de las palabras que inspiran temor, rechazo o pudor." Tradução nossa. 
504 | Angélica Karim Garcia Simão, Maria Angélica Deângeli

observadas formas de abrandá-lo por meio de eufemismos. Antunes (2012, p. 44) chama a atenção para o estudo de diferentes tipos de eufemismos como importantes recursos de textualização, ligando-os à "expressão de valores sociais ou de estereótipos controversos", relacionados à "conveniência da polidez e da cortesia social", e como uma opção contemporânea do "comportamento politicamente correto".

Domínguez (2008) afirma também que, para evitar o uso de uma palavra indesejável, os falantes escolhem um substituto socialmente aceitável para a palavra em questão. O eufemismo, portanto, deve ser ambíguo, de modo que possa ser entendido por seu significado "literal", mas também por sua referência ao termo tabu. Entretanto, deve ter uma conotação atenuadora do disfemismo.

Pode-se depreender, no entanto, que os fenômenos conhecidos como eufemismos e disfemismos são importantes mecanismos que influenciam na atualização do léxico e de sua tradução, o qual se adapta de maneiras diferentes a cada sociedade e aos diversos grupos sociais que a compõem. Apesar das diferenças entre os termos, que variam entre os povos, o tabu permanece.

Com base em tais asserções, objetivamos analisar o léxico tabu presente na obra El hombre de mi vida (2000), de Manuel Vázquez Montalbán, em suas traduções para o francês, L'Homme de ma vie (2003), de Denise Laroutis, e para o português, O homem da minha vida (2003), de Rosa Freire D'Aguiar. Pretende-se observar de que modo o léxico tabu se articula, no texto em espanhol e em suas traduções, (re)criando ou corroborando os sentidos que emergem do texto.

\section{Sobre o autor e a obra}

O escritor Manuel Vázquez Montalbán, além de atuar como jornalista, teve uma longa carreira literária, abrangendo em sua extensa obra vários gêneros, que abarcam desde o ensaio até o romance policial. Sua estreia como poeta se deu na década de 60, no entanto, seu maior reconhecimento e prestígio aconteceram a partir da década de 70 do século XX, com o livro Tatuaje (1973), a primeira obra de uma série de romances policiais protagonizada pelo detetive Pepe Carvalho, que lhe conferiu grande popularidade nacional e internacional.

Os romances policiais da série Pepe Carvalho compõem um total de 24 livros, porém, inicialmente, somente oito deles foram traduzidos para o português brasileiro, enquanto mais da metade das obras que compõe a série foi traduzida para o francês. As traduções, tanto em português como em francês, foram feitas por tradutores variados, fato que 
nos leva a supor que as escolhas tradutórias reveladas pela análise do conjunto das obras traduzidas para esses dois idiomas não estariam atreladas a um estilo tradutório, mas sim a estratégias reincidentes em diferentes projetos tradutórios. Essa particularidade também pode revelar estratégias de tradução convencionadas, especificamente, para a tradução do léxico tabu e contribuir para o entendimento da tradução das línguas envolvidas e das representações culturais presentes nesses contextos.

A tradução para o francês de El hombre de mi vida foi publicada em 2002, pela editora Christian Bourgois, e reeditada pela Éditions du Seuil em 2003, da qual foram extraídos os excertos aqui apresentados. Em português foi lançada em 2003 pela Companhia das Letras.

Escrita em 2000, Manuel Vásquez Montalbán captou previamente com essa obra as insatisfações e desencantos da virada do milênio, que viriam a se concretizar nas primeiras décadas do século XXI. Descrevendo, na voz do detetive Pepe Carvalho, os desconcertos da globalização e da pós-modernidade, considerada por ele como "uma época idiota entre duas épocas trágicas" (2003, p. 20), El hombre de mi vida contribui para a evolução do gênero policial espanhol em um dos seus aspectos mais significativos, sua transformação em um gênero político (COLMEIRO, 2005, p. 18). Como afirma Colmeiro, a nova versão da narrativa policial espanhola traz uma visão desestabilizadora do crime na sociedade, valendo-se deste como um "instrumento de observação social e crítica cultural, assim como espaço de resistência política e subversão ideológica do status quo" ${ }^{224}$. (p. 15)

O retorno a Barcelona num momento de agitação política, depois de algum tempo passado em Buenos Aires, é o pano de fundo das tramas narrativas do romance El hombre de mi vida. O ano é 1999. Barcelona, cidade global e dividida entre as reivindicações nacionalistas e os anseios capitalistas da globalização, é o espaço privilegiado do detetive Pepe Carvalho às voltas com a investigação de um crime que envolve seitas satânicas, partidos nacionalistas catalães e dois clãs políticos rivais, os Pérez i Ruidoms e os Mata i Delapeu.

Ex-agente da CIA, tendo chegado aos sessenta anos e tomado por um certo desencanto da profissão e da vida, Carvalho agora é convocado por Charo, prostituta e ex-amante do detetive, para desvendar um crime de proporções globais. Também de volta a Barcelona, após ter vivido sete

224 "instrumento de observación social y crítica cultural, así como un espacio de resistencia política y subversión ideológica del statu quo". Tradução nossa. 
anos em Andorra, Charo torna-se gerente de uma "butique de alimentos dietéticos e cosméticos naturais" (p. 15), negócio gentilmente montado por seu amigo e novo chefe, Quimet, um catalanista fervoroso, cujo verdadeiro nome é Joaquim Rigalt i Mataplana. O assassinato do filho de Quimet coloca em cena várias personalidades políticas e membros do alto escalão do governo autônomo da Catalunha. No entanto, a dúvida sobre o verdadeiro assassino do jovem permanece até o final da narrativa; pois Montalban, em vez de desvelar uma intriga passional, parece estar mais preocupado em denunciar os protagonistas dos inúmeros crimes perpetrados pela "nova modernidade criada pelas máfias". (p. 264)

Em meio a essa investigação um tanto obscura, eis que ressurge na vida do detetive um antigo caso de amor. Transformada em "mulher dourada" (p. 289), a personagem que reaparece, primeiramente na forma de admiradora anônima e correspondente apaixonada, pois em grande parte da trama ela só se faz presente por meio dos fax anônimos que envia a Pepe, é Jessica Stuart-Pedrell. Filha de um empresário assassinado que "nunca conseguiu chegar aos mares do Sul" (p. 141), Yes, como também é chamada, desperta agora um grande interesse por parte do detetive. No entanto se tratará, para compor com tantos outros detalhes insolúveis da narrativa, de um amor impossível.

Tomada pelos ruídos da globalização e pelos interesses do capitalismo internacional, somente Barcelona ainda é capaz de oferecer a Pepe Carvalho os segredos de uma culinária única, local, com cheiros e sabores quase indescritíveis. $O$ detetive se esmera por revelar em sua narrativa os segredos gastronômicos do próprio Manuel Vázquez Montalbán. Amante da boa cozinha e fino gourmet, nada lhe escapa quando se trata da arte culinária. Para Montalbán e também para Pepe, ou no sentido inverso, para Pepe e também Montalbán, a cozinha é uma metáfora da cultura (KUNTZ, 1998, p. 46).

Absorvido por complexas tessituras políticas, passionais e até mesmo religiosas, que aumentam o vazio de sua existência, ao detetive obstinado de El hombre de mi vida, só resta fazer suas as palavras de Beckett: "Isto não é mover-se, isto é ser movido". (p. 228)

\section{Questões de análise}

"Ler qualquer obra de ficção é um ato simbólico", uma vez que a partir das palavras do autor recriamos nosso próprio imaginário das personagens e dos espaços onde elas circulam (JAMES, 2012, p. 117). Barcelona, lugar no qual transitam os personagens de Montalbán, é também o espaço do crime, das seitas, da manipulação política, da 
memória e da nostalgia. Diferentemente da narrativa policial tradicional em que os espaços, imaginários ou não, são recriados para conferir verossimilhança e credibilidade à narrativa, Barcelona nos é apresentada através dos olhos do detetive Pepe Carvalho como uma espécie de cidaderefúgio entregue às transformações da pós-modernidade.

Wells (2004) afirma que a escrita de Montalbán evoca processos dialéticos que moldam a relação subjetiva entre indivíduos e espaços urbanos, sendo estes ligados por processos histórico-afetivos e sujeitos a mudanças sociais e culturais. O espaço urbano é representado como um lugar de encontros discursivos que permite apreender a intensa trama das situações experimentadas pelos indivíduos.

Assim, podemos observar em sua narrativa um personagem protagonista que reage ao ambiente ao mesmo tempo em que é influenciado por ele, estabelecendo uma relação afetiva conflitante com o espaço urbano. Em alguns momentos, o personagem expressa uma atitude de reconciliação com essa realidade: "Carvalho [...] para lá encaminhou seus passos, num desejo de reler a cidade, de se reconciliar com a vontade de Barcelona, de se transformar numa cidade pasteurizada" (p. 12). Em outros momentos, o sentimento é de desprezo: "Barcelona tinha se tornado uma cidade bonita, mas sem alma, como certas estátuas" (p. 20), ou ainda, “[...] chovia sobre a Barcelona pasteurizada, como se sua pátina de cidade esquizofrênica e tantas vezes melancólica ainda não tivesse sido suficientemente destruída" (p. 293). Também o vemos expressar um certo ceticismo irónico, "Em cima do balcão, perfeitamente alinhados, estavam os montaditos a la vasca, fatias de pão cobertas de lascas de presunto ou carne que haviam se espalhado por Barcelona como uma epidemia de tapas pós-modernas, 'collage e ecletismo"”. (p. 41)

O detetive incrédulo e curioso tenta apreender sua realidade, "mas o que lhe interessava era compreender a nova cidade" (p. 45), definida de muitas formas: "Barcelona, capital absoluta de um ser imaginário chamado Catalunha e capital relativa de uma comunidade relativamente autônoma" (p. 138); descrita também como espaço do acolhimento e do prazer: "ir para a rua, passear, sentir o corpo total de Yes a seu lado, habitando enfim um espaço favorável, só deles, só por eles delimitado pela simples operação de caminharem juntos”. (p. 159)

$\mathrm{Na}$ esfera discursiva, cabe ressaltar que o léxico tabu é muito utilizado pelo autor na caracterização do personagem como um recurso que, tal como exposto por Simão e Seregati (2016), apresenta diferentes 
motivações e funções. As autoras afirmam que os usos dessas unidades lexicais podem expressar, e comumente o fazem, uma marca de distanciamento ou hostilidade em um nível psicológico ou social, o que se caracteriza como uma forma de "descortesia". No entanto, na obra de Montalbán, parecem traduzir um gesto de aproximação, identificação e intimidade entre os sujeitos de determinado grupo, neste caso a relação entre autor e leitor, o que pode ser considerado, segundo alguns estudos, como uma "anticortesia".

É nessa perspectiva que podemos situar os artifícios narrativos promovidos por Montalbán, procedentes da voz atribuída ao protagonista, que se apoia no uso do léxico tabu para manifestar as insatisfações com o seu tempo. Desse modo, embora possamos entender o tabu como um "patrimônio cultural comum" (Cf. XAVIER, 2009, p.60) em diferentes contextos e sociedades, sendo aceito e entendido de diferentes formas em cada uma delas, o uso dessa linguagem é, em Montalbán, um elemento constitutivo da identidade do personagem, intimamente relacionado ao contexto no qual é enunciado.

O uso desse léxico como marca identitária situa Carvalho no lugar do desvio, da marginalidade, não pelo desprestígio social que esses vocábulos tradicionalmente veiculam, mas pelo distanciamento $\mathrm{e}$ desencontro do personagem com relação ao seu espaço e tempo, tal como podemos constatar: "Barcelona [...] teria uma alma nova que Carvalho procurava em seus passeios até admitir que talvez a idade já não o deixasse descobrir o espírito dos novos tempos, o espírito do que alguns pedantes chamavam de "pós-modernidade". (p. 20)

Apresentamos a seguir alguns fragmentos de análise, a partir da percepção do que pode evocar a fala do personagem em espanhol, e do que se dá a ler como tradução dessa palavra em francês e em português, levando em consideração os aspectos léxicos empregados nessas textualidades tradutórias.

\section{Excerto 1}

Jodidos tiempos en los que Satán no quiere perder su alma y los socialistas quieren perpetuar el capitalismo, pero eran jóvenes y tenían toda una vida para irse curtiendo en el aprendizaje de la muerte. Les metió en un cuarto con dos camas bajo la protección de san Jean Genet, patrón laico de la homosexualidad, a no ser que los poderosos atributos de Margalida consiguieran contrarrestar la amnesia heterosexual de Albert. (p. 146) 
Temps pourris, où Satan ne veut pas perdre son âme et où les socialistes veulent perpétuer le capitalisme, mais ils étaient jeunes et avaient toute la vie devant eux pour se tanner le cuir dans l'apprentissage de la mort. Il les mit dans une chambre à deux lits, sous la protection de Saint Genet, patron laïc de l'homosexualité, pour le cas où les puissants attributs de Margalida ne parviendraient pas à vaincre l'amnésie hétérosexuelle d'Albert. (p. 243)

Época infeliz esta, em que Satanás não quer perder a alma e os socialistas querem perpetuar o capitalismo, mas eles eram jovens e tinham uma vida para se tornarem calejados no aprendizado da morte. Enfiou-os num quarto com duas camas, sob a proteção de são Genet, padroeiro laico do homossexualismo, a menos que os abundantes atributos de Margalida conseguissem reverter a amnésia heterossexual de Albert. (p. 244)

No excerto acima, Carvalho se dirige a Albert, filho do poderoso Pérez i Ruidoms, e a Margalida, espécie de secretária-espiã do clã Ruidoms, que tinha como principal tarefa salvar Albert das garras do pai. Margalida era, de fato, apaixonada por Albert, figura que ela julgava doce, generosa e de boa índole; mesmo sabendo da homossexualidade do jovem, ela cultivava a esperança de terminar seus dias com ele. Tal fragmento trata de uma fala de Carvalho aos dois jovens quando eles tentam fugir de Barcelona, pois a máfia queria fazer de Albert o assassino de Alexandre Mata i Delapeu. Carvalho, conhecendo todos os recursos dos quais dispunham os Ruidoms, quase não acreditava na fuga dos jovens, mas estava disposto a ajudá-los. Nas palavras e no pensamento do detetive, os tempos eram mesmo jodidos: Satanás dominava o mundo, os socialistas tinham se rendido à lógica do capital, Albert estava prestes a ser pego e Margalida desejava um amor impossível. O pessimismo que ronda o personagem pode ser observado na forma vulgar como ele expressa os acontecimentos.

Como podemos notar, as opções de tradução, em francês e em português, parecem não adotar o tom de vulgaridade explicitado na língua espanhola. Embora, em francês, o adjetivo pourri (podre) possa expressar a ideia de algo "moralmente corrompido", "nocivo" (ROBERT, 2012), a expressão temps pourri é frequentemente utilizada para fazer menção ao clima. Quando se quer dizer que o tempo não está bom, ou muito chuvoso ou muito frio (un été pourri, un hiver pourri), usa-se a locução temps pourri. No contexto da narrativa de Montalbán, pourri 
510 | Angélica Karim Garcia Simão, Maria Angélica Deângeli

evocaria então o sentido figurado da palavra e não a expressão meteorológica do tempo.

Em português, a escolha do tradutor por "época infeliz" atenua o valor da lexia tabu jodidos. Uma época infeliz é uma época triste, marcada por circunstâncias desfavorecidas (HOUAISS, 2003). O adjetivo infeliz pode significar, no uso informal, desgraça, dano, mas não faz apelo ao tabuísmo evidenciado na língua espanhola. Assim, na tradução brasileira, o leitor parece ter diante de si um detetive mais contido, menos despojado e desbocado, alguém que denuncia os infortúnios de uma época, sem necessariamente refletir essa desilusão na linguagem.

A mesma estratégia de atenuação do léxico tabu pode ser observada nos excertos que se seguem, ora na tradução brasileira, ora na francesa:

\section{Excerto 2}

El enemigo está dentro de nosotros mismos y el muy hijo de puta estudia cada día por dónde puede jodernos y llega un momento en que se da cuenta de que envejecemos de que se nos ha debilitado la defensa y entonces nos ataca por todos los frentes y si puede lo más que nos permite es agonizar bebiendo agua con una pajita o alimentándonos por la nariz. (p. 34)

L'ennemi est en nous, ce salopard surveille chaque jour par quel côté il peut nous baiser et arrive le moment où il se rend compte que nous vieillissons, que nos défenses ont faibli, alors il nous attaque sur tous les fronts et, s'il peut, il nous permettra tout juste d'agoniser en buvant de l'eau avec une paille ou nourris parle nez. (p. 52)

O inimigo habita dentro de nós e todo dia esse grande filho da puta estuda por onde pode nos ferrar e um dia se dá conta de que envelhecemos, de que nossa defesa está mais fraca, a aí ataca por todas as frentes e o máximo que nos permite é que agonizemos bebendo água com canudinho ou nos alimentando pelo nariz. (p. 55)

O fragmento acima se refere a uma fala de Carvalho a Charo, numa das primeiras visitas da ex-amante à casa do detetive, após um longo período de separação. Charo chega de surpresa, e Carvalho calcula que o jantar não será suficiente para duas pessoas. Decide então fazer uma sobremesa. Ao observar que, entre os ingredientes, ele usa frutose, Charo indaga se ele está diabético. Ele lhe responde que não, mas afirma que um 
dia será. Embora Carvalho pareça se reportar a um inimigo bem específico: o açúcar e, consequentemente, o diabetes, o que se pode depreender de seu discurso é que se trata de algo bem mais nocivo. $\mathrm{O}$ inimigo que "habita dentro de nós", "esse grande filho da puta" (el muy hijo de puta), não concerne apenas à doença física; aos olhos de Carvalho, trata-se de um adversário bem mais poderoso que tomou conta dos indivíduos e de suas relações. $O$ inimigo do qual ele fala são os infortúnios da pós-modernidade, as desgraças do capitalismo, o medo, a solidão, a corrupção humana, que confinam o sujeito ao espaço do nada (p. 273). É possível perceber nas palavras de Carvalho a força de um inimigo que só pode querer nos "foder".

Nesse contexto, duas observações merecem ser feitas com relação às traduções. Primeiramente, no que diz respeito à tradução da expressão hijo de puta. Em francês a opção se deu pelo vocábulo salopard que, no uso coloquial, significa "pessoa sem escrúpulo", "filho da mãe", uma espécie de eufemismo para hijo de puta, ao passo que, em português, o tradutor manteve o tabuísmo com a tradução "filho da puta". Por outro lado, o verbo jodernos foi traduzido em francês por baiser, evocando assim o sentido sexual do vocábulo, tal como em espanhol. No entanto, em português, o uso do verbo ferrar não faz apelo à conotação sexual do vocábulo, tal como expresso em espanhol e em francês. Assim, num mesmo excerto, observamos duas tendências tradutórias diferentes, uma explicitando o léxico tabu e outra atenuando sua expressão.

Essa tendência se repete ao longo da narrativa, como podemos constatar nos fragmentos abaixo:

\section{Excerto 3}

[...] incluso Carvalho consiguió precisar la imagen que rechazaba, aquella en que estuvo a punto de encular a Yes y no lo hizo por lo que tenía de simple afirmación de prepotencia y de humillación social, dar por culo a una señorita de casa bien. (p. 98)

[...] et Carvalho parvint même à cadrer l'image qu'il se refusait, celle où il était à deux doigts de sodomiser Yes et y renonçait, parce qu'il y voyait la simple affirmation de sa toute-puissance, une sorte d'humiliation sociale - enculer une jeune fille de bonne famille. (p. 158)

[...] e Carvalho conseguiu até mesmo precisar a imagem que rejeitava, aquela em que esteve prestes a enrabar Yes, o que não fez pelo 


\section{2 | Angélica Karim Garcia Simão, Maria Angélica Deângeli}

que isso significava de simples afirmação de prepotência e de humilhação social, enfiar no cu de uma senhorita de boa família. (p. 160)

Nesse caso específico, o eufemismo ocorre na tradução para o francês com o emprego do verbo sodomiser, cujo registro de língua difere do espanhol encular e também da tradução brasileira, em que se optou pelo verbo «enrabar». Em espanhol, a unidade lexical pertence a um registro de uso vulgar, assim como em português «enrabar» é considerado um tabuismo (HOUAISS, 2003).

$\mathrm{Na}$ fala do detetive Pepe Carvalho, são comuns expressões como hijo de puta, puta vida, coño, mierda, joder, follar, entre outros palavrões, que expressam seu desapontamento diante do mundo. Segundo o detetive "la vida es como la escalera de un gallinero, corta pero llena de mierda" (p. 20); o milênio que estava prestes a começar seria também "este milenio de mierda" (p. 181); a vida não passava de "una puta vida" (p. 7); à mulher por quem se descobrirá apaixonado refere-se como "la vaca del fax" (p. 20).

Trata-se de um detalhe interessante no decorrer da narrativa. Tal como explicitado anteriormente, Carvalho recebe fax de uma correspondente anônima, que será designada, num primeiro momento, como "la vaca del fax" (p. 20); uma vaca "fofa y neurótica" (p. 12). Ele a imaginava "gorda, chaparra, obesa y pedante" (p. 84). No entanto, a esse tom pejorativo usado para se reportar a tal correspondente irá se associar um outro sentimento um tanto ambíguo. A "vaca do fax" revela ser Yes, jovem com quem Carvalho se envolvera em seu passado e que reaparece, agora, como uma linda mulher, casada com um empresário de sucesso, mãe de dois filhos maravilhosos, enfim, a "mulher perfeita", "a mulher dourada" (p. 144) que ele esperava desde a infância. Yes era a única pessoa, além de sua própria mãe, que o chamava de José e se mostrava assim verdadeiramente próxima do detetive. Essa identificação da mãe na mulher desejada é revelada pelo próprio Carvalho no final do romance. Quando recebe a notícia da morte de Yes, vítima talvez de assassinato pelo próprio marido, o detetive não pode deixar de expressar seu sentimento:

Madre desnuda. Frente a las madres vestidas algunas mujeres excepcionales se nos ofrecen como madres desnudas y de una $u$ otra manera las matamos. (p.180) 
As traduções de El hombre de mi vida para o francês e o português: léxico e diferença | 513

Mère nue en face des mères habillées, quelques femmes exceptionnelles s'exposent devant nous en mères nues et, d'une manière ou d'une autre, nous les tuons. (p. 292)

Mãe nua. Diante das mães vestidas algumas mulheres excepcionais se oferecem a nós como mães nuas e de uma forma ou de outra nós a matamos. (p. 292)

Morte física e simbólica, Yes terá sido a mulher, como o foi a mãe, que Carvalho amou verdadeiramente, a mulher de sua vida.

No que diz respeito às traduções dos excertos em que figura o vocábulo "vaca", notamos que tanto em francês quanto em português o tom da fala se manteve coerente com aquele empregado em espanhol, sendo traduzido respectivamente por vache e "vaca", como podemos observar nos exemplos que seguem:

\section{Excerto 4}

¿A qué pétalo se refería la vaca del fax? No podía ser otra cosa que una vaca acechante con sus cuernos desportillados y tetas cargadas de leches con sabor a peladillas [...]. (p. 20)

De quel pétale voulait parler la vache du fax? Elle ne pouvait être qu'une vache à l'affût, avec des cornes épointées et des mamelles remplies de lait fleurant la dragée [...]. (p. 30)

De que pétala a vaca do fax estava falando? Só podia ser uma vaca à espreita, com chifres lascados e as tetas carregadas de leite com sabor de pesadelo [...]. (p. 33)

Ou ainda:

\section{Excerto 5}

Al fin y al cabo la prensa habia hablado alguna vez de sus investigaciones, pero entre Carvalho y Julio Iglesias habitaban millones de héroes de papel que se merecian que una vaca fofa y neurótica les enviara un fax. (p. 12)

La presse avait parlé plusieurs fois de ses enquêtes après tout, mais, entre Carvalho et Julio Iglesias il y avait de la place pour des millions de héros de papier qui méritaient qu'une grosse vache névrosée leur envoie un fax. (p. 16) 
Afinal de contas, a imprensa tinha falado uma ou outra vez de suas investigações, mas o mundo entre Carvalho e Julio Iglesias era habitado por milhões de heróis de papel que mereciam receber um fax de uma vaca balofa e neurótica. (pp. 18-19)

Somente em uma das ocorrências, a tradução para o português parece amenizar o sentido da fala de Carvalho. Trata-se do momento em que Pepe reencontra Yes e, surpreso, diz a si mesmo que ela era uma mulher muito bonita para ser a "la vaca del fax". Nesse caso, a tradutor optou, em português, pelo vocábulo "imbecil”, que parece não expressar a mesma força depreciativa evidenciada pela palavra "vaca". "La vaca del fax", em espanhol, e, em francês, "la vache $d u$ fax", são a expressão dessa mulher desconhecida que interpela o detetive em sua vida privada, que se oferece a ele de maneira insistente, se insinua, quer tê-lo como o homem de sua vida. Vaca assim como vache fazem apelo ao sentido pejorativo da palavra. Não seria, a nosso ver, o caso do vocábulo "imbecil", que estaria relacionado a uma capacidade mental, denotando uma pessoa "tola", de "inteligência curta" (HOUAISS, 2003), e não se referindo a um comportamento vulgar.

\section{Excerto 6}

Era una bella mujer, demasiado bella para poder creer que fuera la vaca del fax, pero se fue acercando y se estrecharon las manos estudiándose. (p. 86)

C'était une belle femme, trop belle pour qu'il pût croire que c'était la vache $d u$ fax, mais il s'approcha et il se serrèrent la main en s'observant.(p. 140)

Era uma bela mulher, bela demais para que pensasse na imbecil do fax, mas ele aproximou-se e, estudando um ao outro, apertaram-se as mãos. (p. 141)

\section{Considerações finais}

Se a vocação da palavra traduzida é desvelar o interstício que a separa de si mesma e do outro, instaurando uma falha originária do dizer e de seus possíveis sentidos, as leituras das obras aqui apresentadas perfazem o percurso de uma letra que sempre se destina a interpretações diversas, num movimento de abertura contínuo dessa falta original. $\mathrm{O}$ que se busca apreender desse exercício de leitura é o que ele próprio 
oferece na diferença constitutiva de sua expressão: um dizer múltiplo, em diferentes línguas, traduzido de formas variadas.

Nesse percurso de leitura que também se fez diverso, as diferenças lexicais que procuramos enfatizar nas traduções da obra de Manuel Vázquez Montalbán para o francês e o português são frutos de um dizer tradutório heterogêneo, concebido como diferença naquilo que seria sua língua supostamente original, ou seja, o espanhol, não sem esquecer a “origem" catalã do escritor.

O primeiro tempo, para retomar Crépon, da leitura de Montalbán, já é um tempo permeado por outras línguas e culturas; é o tempo-espaço de um escritor cosmopolita, reivindicando um pertencimento catalão sem, de fato, o fazer. Assim, a língua espanhola é também na obra do autor um gesto político, a expressão de uma "marginalidade global", de um mal-estar contemporâneo que se quer dizer em todas as línguas do mundo, de uma palavra que apela incessantemente à tradução.

Dessa forma, não se trata de evocar as diferenças de tradução aqui esboçadas como episódios discursivos intramuros. A fala do detetive Pepe Carvalho em sua Barcelona jamais esquecida se faz ecoar de diferentes formas nos diversos espaços em que é ouvida.

Somos assim confrontados, em qualquer língua que se apresente a narrativa, a uma palavra errante, um léxico plural, cuja singularidade se encarrega de dar voz a um personagem também errante, já um pouco cansado da vida e das agruras dos tempos modernos.

Esse desencanto se faz sentir em suas palavras, que se concebem no interstício da memória, pois há sempre uma nostalgia em Montalbán, e da denúncia, sua narrativa pode ser lida como um "gênero político", e são reinventadas a cada momento. Invenção de uma língua que inventa suas traduções. É nesse sentido da palavra múltipla e da (re)invenção incessante que somos movidos por essas textualidades tradutórias em suas línguas (quase) originais.

\section{REFERÊNCIAS}

ANTUNES, I. Território das palauras: estudo do léxico em sala de aula. São Paulo: Parábola Editorial, 2012.

BATISTA, R. O. A palaura e a sentença. São Paulo: Parábola Editorial, 2011. 
516 | Angélica Karim Garcia Simão, Maria Angélica Deângeli

CRÉPON, M. (2004). A tradução entre culturas. Tradução de Henrique Oliveira Lee, Vinícius Pereira Carvalho e Arildo Leal de Paula Junior. Cadernos de Tradução, Florianópolis, v. 36, n. 2, pp. 254-289, maio-agosto, 2016.

Disponível em:

<https://periodicos.ufsc.br/index.php/traducao/article/view/2175. 7968.2016v36n2p254> Acesso em: 10 jun. 2017.

DOMÍNGUEZ, P. J. C. Tabú y lenguaje: las palabras vitandas y la censura lingüística. Thémata. Revista de Filosofía, v. 4, n. 40, pp. 31-46, 2008. Disponível em <https://revistascientificas.us.es/index.php/themata/article/view/599>. Acesso: 22 fev. 2019.

HOUAISS, A. Dicionário eletrônico Houaiss da língua portuguesa. Rio de Janeiro: Objetiva. Versão 3.0.1 [CD-ROM]. 2003.

HWANG, D. A. Lexicografia: dos primórdios à Nova Lexicografia. In: HWANG, A. D.; NADIN, O. L. Linguagens em interação III: estudos do léxico. Maringá: Clichetec, pp. 33-44, 2010.

KUNTZ, L. I. Manuel Vázquez ou la liberté. Le Courrier de l'UNESCO, 51, 10, p. 46-50. Disponível em: <https://unesdoc.unesco.org/ark:/48223/pf0000113615_fre〉. Acesso em: 24 jan. 2019.

MONTALBÁN, M. V. El hombre de mi vida. Lectulandia (Digital), 2000.

MONTALBÁN, M. V. L'homme de ma vie. Tradução de Denise Laroutis. Paris: Seuil, 2003.

MONTALBÁN, M. V. O homem da minha vida. Tradução de Rosa Freire D’Aguiar. São Paulo: Companhia das Letras, 2003.

NUNES, J. H. Lexicologia e Lexicografia. In: GUIMARÃES, E.; ZOPPIFONTANA, M. (Orgs.) A palavra e a frase. São Paulo: Pontes, 2006.

ROBERT. (2012). Le Petit Robert. França: Le Robert.

RODRIGUES, C. C. Tradução e diferença. São Paulo: Editora Unesp, 2000.

RODRIGUES, C. C. Estudos da Tradução. In: GONÇALVES, A. V.; GOIS, M. L. S. (Orgs). Ciências da linguaguem: fazer cientifico? Campinas: Mercado de Letras, 2012.

SHADID, A. C. Sobre el tabú, el tabú lingüístico y su estado de la cuestión. Kánina (Online), v. 35, n. 2, pp. 121-125, 2011.

SIMÃO, A. K. G.; SEREGATI, F. Léxico tabu em "Los mares del sur", de Manuel Vázquez Montalbán. Letras $\mathcal{E}$ Letras, Uberlândia, v. 32, n. 1, pp. 62-90, 2016. 
As traduções de El hombre de mi vida para o francês e o português: léxico e diferença | 517

XAVIER, C.D.S.A. Esbatendo o tabu: estratégias de tradução para legendagem em Portugal. 2009. Dissertação (Mestrado em Estudos Anglísticos) Faculdade de Letras, Universidade de Lisboa, Lisboa.

WELLS, C. Urban Dialectics in the Detective Fiction of Manuel Vázquez Montalbán. Forum for Modern Language Studies, v. 40, n. 1, pp. 83-95, 2004.

Recebido em: 23/08/2019

Aceito em: 15/09/2019 